\title{
The Zadeh Project - A Frame for Understanding the Generative Ideas, Formation, and Design
}

\author{
Mark J. Bliton and Stuart G. Finder
}

\begin{abstract}
"Taking things for granted" is a phrase which, taken literally, would be morally legitimate if we realized that this was really a "grant," an unearned gift.
\end{abstract}

Herbert Speigelberg (1975)

\section{Ideas Behind the Initiation of the Zadeh Project}

This book represents a unique contribution to the field of clinical ethics consultation. What might seem at first glance to be an anthology, that is, a collection of independent essays, is actually more akin to a conversation, a shared engagement, a mutual undertaking. At the center of this conversation is a steadfastness, abiding and serious in its orientation - exemplified in these voices and contributions collected from colleagues - to explore, identify, and examine the actual conduct of individuals who engage in ethics consultation practice. Although there is some helpful resemblance to an anthology, for example in the variety of ways these essays describe and depict a complex array of different standpoints regarding the practical and conceptual commitments in this growing field, more important to the Zadeh Project is the deliberate focus on explicating and probing the ways these commitments influence how a particular individual acting as an "ethics consultant" might understand and interpret the roles and prevalent expectations represented by those differing standpoints. In that light, and perhaps more urgently, this book is motivated by a mutual recognition that part and parcel with the responsibility of doing

\footnotetext{
M. J. Bliton ( $\triangle)$

Medical Bioethics, Kaiser Permanente Los Angeles Medical Center, Los Angeles, CA, USA e-mail: Mark.J.Bliton@kp.org
}

S. G. Finder

Center for Healthcare Ethics, Cedars-Sinai Medical Center, Los Angeles, CA, USA

e-mail: Stuart.Finder@cshs.org 
clinical ethics is an ongoing and clear need to describe and consider what clinical ethics consultants actually encounter when actively working with physicians, nurses, social workers, and other healthcare providers as well as with patients, families, and others who care about patients. As a contribution to that necessity of being accountable, this Project and the resulting book represent much more than merely collecting together the thoughts and perspectives of a group of colleagues from within a common field: this book is an attempt to display, to model through written text, a set of practices and what is at stake in these practices.

Like any collective effort of this sort, the Zadeh Project has a history and context that situates the story of its development. It began, first and foremost, with an actual clinical ethics consultation, after which, as part of the effort to reflect on what had occurred during that consultation episode, words were committed to the page and the end result was a manuscript: the Zadeh Scenario developed and written by Stuart Finder (2018). The Project also grew out of our previous investigations, writing, and publications regarding a central idea: writing about clinical ethics consultations can be - and more importantly needs to be - understood as a form of inquiry, even discovery, about the facts, perspectives, commitments, and interpretations regarding what is most worthwhile to those people most intimately involved in what are typically called "ethics cases" (Bliton and Finder 2002; Bliton 2005; Finder and Bliton 2008, 2011). Throughout this Project, the Zadeh Scenario has thus served as the touchstone, the independent variable, if you will, that remains constant. The text for this Scenario was not edited nor revised over the course of this Project. It has remained intact, word for word (several typos, understandably, were corrected prior to publication here) as initially written and then shared, first with Bliton, as part of Finder's effort to gain some understanding about the experience it captures. In this way, the Zadeh Scenario has served as the locus for primary examination and critical interpretation from the start.

Using the Zadeh Scenario in this way demonstrates another prominent theme for this book, namely, that the clinical and moral work of clinical ethics consultation is primarily communicative, involving many varied forms of telling and listening which thereby elicit additional repetitions, including written forms, to establish clearly, to the extent possible, what is morally relevant (Zaner 1993, 1998, 2004a, b). This kind of repetition and focused examination was modeled throughout the different stages of the Zadeh Project, including the design and format for the book. The Project began in earnest when we first solicited critical views from colleagues beyond our own immediate group, colleagues who represent a considerable range among contemporary standpoints regarding clinical ethics.

Specifically, the discussions that formed the Zadeh Project were initially carried out in a series of presentations conducted at several national and international Bioethics and clinical ethics consultation conferences. The first was a panel discussion at the 6th International Conference on Clinical Ethics Consultation, in Portland, Oregon, during May 2010. Encouraged by the response we received from both our collaborators for that panel and the audience who attended the presentation, in 2012 at the 14th Annual Meeting of the American Society for Bioethics and Humanities, 
then again with a different set of colleagues in 2013 at the 9th International Conference on Clinical Ethics Consultation at Klinikum Ludwig-MaximilliansUniversity in Munich, Germany, we conducted extended workshops in order to examine more fully the complex set of themes which emerged in the initial panel, namely, themes regarding moral experiences encountered in "doing" ethics consultation as well as the sort of assessments encountered in peer review. In all three professional presentations, we explicitly told our colleagues who presented with us and those in the audience that the Zadeh Scenario manuscript was being used to evoke, to allude to, to bring into the discourse with our audiences a recognition of the varieties and different modes of communication that often emerge in clinical discussions about what really matters to the people involved.

More importantly, especially for the two workshops, we engaged in these explorations with an explicit acknowledgement of our own commitment to examine those frequent occasions in which the words, interactions, and different ways of "listening and talking" in clinical encounters are key indications about what matters in the experiences of those people most intimately and personally involved. Indeed, then as now, we acknowledged that from the very moment ethics consultants begin interacting with a patient, a family, or other healthcare professionals, those same ethics consultants may come into direct contact with experiences that are frequently overwhelming to these other persons' lives. What is required from ethics consultants, especially at the very beginning of such interactions, therefore, is a careful and practical kind of listening and talking by which to identify and measure how to help those others think about their own beliefs and values, and to help these people understand the issues posed by their own circumstances, as well as to help them anticipate, and then consider, the ways to best face their circumstances in the present and going forward into the future. As Richard Zaner puts it, to "enter a clinical situation is invariably to encounter a multitude of voices - at times muted, at others pleading, at times a veritable cacophony" (Zaner 1998: 69). "Working within such a resounding legion of voices," Zaner says elsewhere, "is surely one of the most striking factors about being involved as an ethicist in clinical encounters" (Zaner 2015: 114). "Thus," he continues, "the image of 'voices' - challenging, compelling, urgently seeking to be heard - and the exigencies of time - time to think about matters, time to speak and be heard, time to listen, time to settle disputed things" are themes that run through every clinical encounter (Zaner 2015: 114).

The panel and subsequent workshops were thus designed around this focus on careful and practical listening and talking in order to raise, explicitly, these themes of voices and time in discussions about clinical ethics. Likewise, these were designed to examine deliberately whether, and to what extent, these integral activities of talking and listening are recognized as essential for the practices of clinical consultation about ethics. The idea, in keeping with Zaner's "multitude of voices," was that such talking and listening consists in recognizing the interests and attention, the threats, agreements, expectations, memories, indications, faith, suspicions, trust, even promises and deceptions, of those individuals immediately involved in a particular clinical situation. 
We therefore conducted all three of these conference-based sessions with different groups of ethics consultants and Bioethics colleagues - this too was a deliberate and intentional way to explore how discussions that are conversational and in person, as exemplified by participation in those conference settings, provide immediate examples and reflect (or not) typical assumptions about roles, participation, subjectmatter content, context of interaction, and so on. Of course, such assumptions inform and yet also limit both the type and extent of clarifications that may occur in professional discourse. For example, topics in clinical ethics, or Bioethics more generally - for instance, discussions about a patient's dying or decisions to limit the provision of medical interventions - are assumed to be similar across settings or contexts. What we sought to explore are the ways that contexts, presuppositions, and roles may be relevantly different in these different circumstances; for example, when participating on a Medical Center Task Force or in institutional committee meetings, the vocabularies, the conversational tone, and length of time spent to explain the moral contents and practical implications may be quite different from expressions used for those same elements during clinical meetings with patients, providers, family members, and so on. Therefore, recognizing and responding to differences among these kinds of activities becomes crucial to clinical ethics practice in health care environments. Moreover, the meanings of ethics topics, their presuppositions, and the vocabularies used must be understood as directly correlated to the specific kind of circumstances and the specific kind of attention directed to those circumstances - which serves to distinguish what is relevant and what is not (Schutz 1967a: 73). ${ }^{1}$

The same need to distinguish relevant differences among related activities would thus seem to arise when called to understand and respond to writing in or about clinical ethics, e.g., an ethics consultant's personal notes, chart notes, case presentations, and so on. ${ }^{2}$ These activities organize different kinds of documentation. They divide it up, create some order for it, even arrange it among various levels, including the distribution of what is written in different contexts across time. This need to

\footnotetext{
${ }^{1}$ Following Schutz, Richard Zaner (Zaner 1988, 1998, 2004b, 2006), and others like Arthur Kleinman (Kleinman 1988, 2006) and Arthur Frank (Frank 1997, 2001) show the ways clinical medicine and clinical ethics embody entire sets of deeply sedimented assumptions about multiple roles and interactions, which themselves presuppose additional theories about interpersonal relations and communication. Given that any adequate examination of the methodologies needed to understand these social, clinical, and interpersonal relationships, and communications would require a daunting combination of wide-ranging conceptual and empirical studies, there is much work that remains to be done, although there have been significant contributions made in a number of specific enclaves which inform the activities of clinical ethics consultation (See, Starr 1982; Zussman 1992; Anspach 1995; Fox and Swazey 2008; Bosk 2009; Evans 2012; Kaufman 2015).

${ }^{2}$ For example, the topic of writing and placing of a chart note in the medical record represents consistent focus for discourse, argument, and claims made about the relevance of clinical ethics consultation to the identification, clarification and resolution of moral issues in health care. These arguments and claims have continued throughout the development of the field (see Freedman 1993). Nancy Dubler and the Working Group for the Clinical Ethics Credentialing Project have made charting the centerpiece of their argument for credentialing clinical ethics consultants, (see Dubler et al. 2009; Bruce et al. 2014).
} 
distinguish holds even more pointedly for writing intended as a critical or interpretive commentary about a particular situation, topic, or theme for professional presentation and publication.

Therefore, another question we put to our collaborators as part of those conference presentations - and which we similarly asked of the contributors for this written version of the Zadeh Project - was to consider just how - that is, in what ways - would those interactive elements of ethics consultation, documentation, and various forms of writing figure into and be accounted for in peer review $?^{3}$ After all, among the most serious questions that any ethicist must engage, surely one primary task is that of finding the best way, and to employ the most faithful way, to express the complex range and scope of moral considerations that are generated as well as evoked throughout ethics consultation work (Chambers 2000; Molewijk et al. 2016).

Building upon what we experienced and learned from doing the panel in Portland back in 2010 and then in the subsequent workshops in 2012 and 2013, this book is designed to solicit and explore just these kinds of practical issues that emerge among the multiple explanations about the moral experiences and content encountered when "doing" ethics consultation - as well as to solicit and explore what else might be learned about such "doing." Accordingly, the variety of assumptions and assessments presented by the essays published here may be taken as representing additional ways to understand Zaner's recognition of the challenging and compelling voices that need to be heard. Accordingly, there is no single, determinate story or authoritative voice in this Zadeh Project. Instead, it presents a mosaic composed of diverse standpoints, multiple variations expressing similar and related themes, and generates a manifold of questions and different voices, as well as valuable criticisms. These, of course, all need more explicit and careful investigation as the field of clinical ethics consultation grapples with the demands of personal and professional obligations inherent to clinical work and the extensive scope of professional responsibilities that confront future development. The Zadeh Project, therefore, is not designed to provide definitive answers but to evoke and provide some shape for pertinent questions and inquiry.

For our own part, we maintain that these recognitions and responsibilities are generated in the necessary and crucial influence of the "clinical turn" in ethics, which has been exemplified in the work and publications by Zaner and others (Zaner 1988, 2006; Andre 2002; Churchill et al. 2013). This "clinical turn" demonstrates the need to pay explicit attention to what is commonplace, the taken-for-granted in everyday life, and reveals how it is there that moral experience and ethical significance are rooted (Zaner 1984; Hoffmaster 1992). Having taken that 'turn,' not only are we quite cognizant of the variety of ways the roles for clinical ethics are

\footnotetext{
${ }^{3}$ Proposals have been published recently by a number of scholars, (see discussions in Fins et al. 2016 and Pearlman et al. 2016).

${ }^{4}$ In this sense, the Zadeh Project may be placed alongside such previous efforts as Andre 2002; Zaner 2004a; Ford and Dudzinski 2008.
} 
conceptualized, ${ }^{5}$ but we are committed to maintaining such diversity of expression. Such is the grounding frame for the Zadeh Project and hence this book.

\section{A Brief Explanation of the Method Used in the Design for the Zadeh Project}

In light of the groundwork and frame discussed above, this book is organized around a practical feature of professional life that sociologist Harold Garfinkel termed a "documentary method of interpretation" (Garfinkel 1967: 76-103). With roots in the work of Alfred Schutz and Aron Gurwitsch in phenomenology and social psychology, the "documentary method of interpretation" uses the idea that in ordinary everyday life what we experience is typically understood as presenting or reflecting underlying (and presupposed) patterns of belief, expectations for interactions, and their meanings. ${ }^{6}$ To better understand what others hold to be worthwhile requires probing with them what is at stake, what is most cherished within those beliefs, identifiable values, stories, and situations that are presented as meaningful. This rationale provides the key to following the development of explanations and critiques throughout the sections and chapters that compose this book, and likewise provides a way to integrate and make sense of the observations and themes gathered from one chapter or another by reference to that larger context of the Zadeh Project.

As mentioned above, the unaltered Zadeh Scenario has remained the touchstone throughout this Project. Therefore, a specific set of observations by one author using, for example, a conversation between Finder and the patient's daughters, or the dialogue between Finder and Dr. Broukhim can be seen as a document - or in other words, an instance of - a manifestation, possibly a symptom or an indication, of a particular kind of issue. And, the variations among the ways that these instances are discussed in the different contributions can be compared in order to identify those additional assumptions used by these authors to create and support an assessment of clinical ethics consultation.

\footnotetext{
${ }^{5}$ The breadth of different concepts may be found in such works as Jecker et al. 2012; Gaines and Juengst 2008; Aulisio et al. 2003; Engelhardt 1996; Jonsen and Toulmin 1988.

${ }^{6}$ For Garfinkel, the initial conception and development for this method was for conducting the work of social scientific studies, in which Garfinkel elaborated on Schutz's interest and insight regarding the ways that schemes of relevance are used in what Garfinkel called "common sense knowledge of social structures" (Garfinkel 1967: 76). Likewise, Schutz's explication of sociality has been decisive for Zaner's investigations into many enclaves of meaning in clinical medicine and clinical ethics, for example the relationships among physicians and patients, the illness experience of patients - as interpreted by patients, then physicians and others, the core moral elements of responsibility, and the imperative to not take advantage of patients (see especially Zaner 2004b). More specifically, a theme prominent for Zaner, and for the Zadeh Project, pertains to those communicative dimensions where Zaner so brilliantly extends Schutz's ideas about "face-to-face" and the attitudes of "taken-for-grantedness" into his own investigations of moral and clinical life.
} 
This method thus serves as a key because it enables the readers to trace out various responses to those issues, as well as the interpretive themes that emerge among the essays. Likewise, this method demonstrates the similarities and critical differences among the ways this Zadeh Scenario is read by the contributors, specifically in the way that several direct their focus on procedures and rules, thereby documenting implications for the meanings assigned to 'ethics', as well as the different ways the range of questions and issues are presented.

To help frame that crucial topic which focuses on rules and procedures for ethics consultation, consider one widely used conception of clinical ethics employed when ethical troubles or "problems" arise. Where these troubles call for a response, the role of clinical ethics consultation is to operationalize the way healthcare institutions respond to these "problems" (Curtis et al. 2012; Nelson 2010; Foglia 2012). In addition, this view illustrates a tendency in writing about clinical ethics. Problems, issues, concerns, and topics are called "ethical" in ways that do not seem to have faced or, at a minimum, are remote from the bristling thicket of emotions and faceto-face interactions that frequently provide clues to identifying those values that people hold most worthwhile in clinical situations (Komesaroff 2001; Molewijk et al. 2011). The characteristic assumption at the organizational level is that the function, the job, of ethics consultation is to make those sorts of problems recognizable as "typical," and then to use standardized expectations, policies, norms, and so on to explain how and why to respond (Frank 2004; Bruce et al. 2015).

With that reliance on standardized expectations, policies, and procedures for conducting clinical ethics consultations, the focus shifts from talking about the moral reasons and actions that prompted those expectations, policies, procedures and so on, in the first place to the effective fulfillment or completion of the designated procedures, so that "ethics" becomes a set of procedures performed in an accountable way. ${ }^{7}$

The "documentary method" used throughout this book therefore provides a practical means by which to identify and interrogate - with a degree of rigor appropriate to the level of investigation - what is morally at stake in, and possibly neglected by, that complex network of discrete and multiple forms of communication and interactions in clinical situations (Natanson 1970; Zaner 1981; Rogers 1983). This method

\footnotetext{
${ }^{7}$ The significance of this substantive and practical issue becomes powerfully evident when we realize, as discussed by Alasdair MacIntyre in his generative book, After Virtue (MacIntyre 1984), that in a pluralistic society like ours there are not only any number of different ethical viewpoints, but that these are deeply at odds with each other. Although each of them may be perfectly self-consistent, each starts from quite different basic premises that rival others. Thus, substantive moral problems continue to arise when "ethics" is used as the means to "fill in the appropriate "moral" or "values' stance" category in a procedure authorized by an organization. The typical, and expected, result is to "manage" the problem by the ethics consultant determining which of the competing values or viewpoints is to be authorized to rule in the clinical decision or negotiation. In the case of conflict between two different standpoints, momentous problems arise, because such conflict resists being resolved equitably, due to that lack of a coherent rule of judgment applicable to both standpoints. Of course, rules can be, and indeed are, stipulated that a consultant simply 'follows the procedure' to create a result. The effect, however, merely documents another standpoint in conflict with the ones that this procedure is intended to resolve, and so on.
} 
can thus be used to investigate additional organizational attitudes and beliefs that underwrite those expectations, norms, and interactions.

In that context, another rationale for utilizing this method as a key component of the Zadeh Project involves an analogy used by Zaner (whose work is deeply rooted in the same phenomenological tradition as that of Schutz, Gurwitsch, and Garfinkel). Zaner's idea is that a clinical ethics consultant works like a sort of clinical detective, and as an interpreter of those "texts" and "documents" created amidst that confluence of individuals, relationships, interactions, and environments in clinical encounters. ${ }^{8}$ This dual analogy of clinical detective and interpreter of "texts" and "documents" is based on the parallel assumption that these multiple sets of activities (detecting and interpreting) use everyday, practical knowledge about social structures, typical behaviors, and patterns of interpretation in clinical environments. These activities also exemplify Schutz's insight that the work of identifying the meanings of those structures, behaviors, and patterns, their presuppositions, their languages, their usage, and so on, directly correlates to the specific kind of attention directed to the circumstances (Schutz 1967a; Schutz and Luckman 1973). Thus, the documentary method, with its embrace of disciplined discovery and self-conscious interpretation, emphasizes - even insists - that one follow the questions threaded and woven across events to trace the senses of meaning evoked in clinical circumstances.

Indeed, our readers will notice that this same idea is used to thread and tie the different sections of this book together. Interpretations in the chapters that follow the Zadeh Scenario illustrate important elements regarding what is often taken for granted in actual consultations as well as bring into highlight the contributors' own documentary style, because their interpretations employ both personally and professionally derived everyday knowledge about social structures, roles and relationships, typical behaviors, patterns of interpretation, legitimate vocabularies, and communication styles in clinical as well as more extensive healthcare environments. By highlighting these implications among different levels of inquiry, the aim is to offer our readers a means to trace the style and content of interpretations used by our contributors in order to raise questions and, likewise, to link, correlate, and contrast the themes presented in different sections of the book. Used this way, the documentary method of interpretation can be focused to raise more explicitly the considerations about discernment and delineation of issues and problems at different levels of clinical engagement, including critical assessment about writing about clinical cases and clinical ethics consultation.

\footnotetext{
${ }^{8}$ In Ethics and the Clinical Encounter (Zaner 1988/2002), Zaner elaborates to say, "The "detective work' or 'circumstantial understanding' is an expanded form of the 'documentary method of interpretation,' a methodical rendering of the central concept of context [which he had explored in depth in Zaner 1981] and its moral equivalent, enablement or empowering" (285). In Troubled Voices: Stories of Ethics and Illness (Zaner 1993) he puts it this way: "ethicists help pick out key decision points and options. They help people go through their options and possible outcomes in the light of their own concerns and values, finding what seems most reasonable to them. As the meaning of obscure texts rarely jumps out and announces itself to the reader, the ethicist needs to become a sort of detective, collecting and probing clues and hints" (151).
} 


\section{Organization of the Book}

The book is composed of 6 sections, the first of which is this Introduction. Next comes Part One, which is the Zadeh Scenario. Part Two then consists of 5 chapters which present critical reviews of Finder's participation as an ethics consultant as presented in the Zadeh Scenario. Part Three consists of 4 chapters which comment and critically reflect on the Zadeh Scenario as well as the issues raised and methods used in Part Two. Part Four presents 3 chapters which each review the implications for peer review raised by their interrogation of the questions generated by the initial 5 critical reviews of Finder's participation in the ethics consultation presented in the Scenario and combine that review with assessment and critical evaluations of the commentaries about method gathered from the four chapters in Part Three. The final section, Part Five, is a reflective summary and response to several of the more significant considerations raised by the commentaries followed by a more general summary of implications for clinical ethics practice that emerge from this entire effort, i.e., from the Zadeh Project itself.

Our premise for organizing the book in this format is fairly straightforward, although not simple. For each Part, the themes developed in each essay represent a specific approach to the same text - the Zadeh Scenario. We asked each contributor to address his or her own understanding of the conceptual and practical commitments prompted by reading this Scenario, and to write a chapter which reflected those issues they thought merited careful discussion. As the book progresses through each succeeding Part, the authors, by reflecting on all the preceding essays, were tasked with identifying, assessing, and responding to the cumulative increase in the complexity and layering of issues, questions, and methods. These themes, issues, topics, and even lists developed and interrogated by our colleagues serve to demonstrate the multiple perspectives that can be focused on a specific, and fragmentary, expression about everyday clinical ethics encounters. As a key result of this design, the thematic variations among different contributions can be explicated as a means to further identify and emphasize which among all those themes, issues, topics, and so on warrant additional explanation and critical interrogation. Akin to how conversations unfold - and more significantly, in ways analogous to involvement in actual ethics consultation situations - the rewards for this effort are stimulating, intriguing, complex, and relevant.

\section{The Zadeh Scenario: An Unaltered Fragment}

As noted, we submitted the Zadeh Scenario to each of our collaborators - in the same manuscript form found (sans typos) within this volume - for those conference sessions we conducted, and likewise to each of the contributors to this volume. However, it must be explicitly stated again that this manuscript was not written for the sake of engaging in these kinds of shared activities. The motivation, rather, was 
much more personal and specific: an attempt to capture, perhaps in some coherent way, a variety of moments in the experience of actually doing ethics consultation so as to (hopefully) better inform the author (Finder) about his own practice. It was only after the fact, when the Scenario had been shared (with Bliton) that the idea began to emerge that sharing it more broadly might serve as a device through which to learn with others, not merely what they might identify as significant in what Finder did (or did not do) but how, in that process of review, the commitments these collaborators see as important for themselves in their own practices could also be shared.

Because it was not intended to be a full and complete rendering of all that a clinical ethics consultant does while conducting ethics consultation, the Zadeh Scenario presents a "problem," in that is does not exhibit several elements typically assumed for published "ethics cases." Accordingly, this Scenario must be understood, quite plainly, as a fragment. The Scenario nevertheless does pose questions about where, or how, it does, or could, fit into a more complete story.

In that way, although the Zadeh Scenario is not an "ethics case" in the typical way that "ethics cases" are published, there are surely implications which are treated that way by our contributors. Perhaps we should say that instead of representing a "case," this Scenario, as a fragment, is unfinished. This characteristic itself presents crucial implications regarding the sets of assumptions and relevant features now "documented" by the critical inquiries presented in the essays that follow. As Lisa Rasmussen proposes in her essay, the Scenario presents a "lens of a case narrative that is necessarily limited (because it is a distillation of an experience lived through days and weeks of interaction with many people)" (Rasmussen 2018: 151). Indeed, that limitation sets up the range of interpretations generated in the different sections and throughout this volume. For example, Tarris Rosell and Brit Johnson ask at the beginning of their essay a question fundamental to the Project: "Was this an "ethics consultation," or something else entirely? Perhaps it began as an ethics consultation and became something else, or began as something else and became an ethics consultation" (Rosell and Johnson 2018: 99-100). Each reader of the Scenario begins by encountering that question in her/his own way, and hence, from the beginning, it has provided a stable document through which to explore a variety of presumptions and commitments regarding what ethics consultation is, what characteristics delineate "good" clinical ethics practice, which questions demand a response, and so on.

In that light, additional clear questions can be anticipated, and demand emphasis: is writing, or "writing-up," a clinical ethics case consultation presumed to be a kind of clinical report, as it were, a "telling" of the "facts" about "what actually occurred" - where 'actually' is presumed to carry with it the sense of a description of what really and truly happened, and hence what is to be taken as most important? (Zaner 2015: 162-3). If so, how should all of the details that are provided in Finder's telling be conveyed?

\footnotetext{
${ }^{9}$ Tod Chambers and others have argued that writings in bioethics, and more specifically writing about cases in clinical ethics, have their own set of literary devices and rhetorical appeals which,
} 
As we emphasized above, one evident characteristic of clinical practice displayed by the Scenario is a kind of primacy for the conversations and interactions an ethics consultant encounters when entering into a patient's and family's life. Another primary question to be addressed regards how, in what ways precisely, does this talking and listening figure into any evaluation regarding practices of ethics consultation in clinical environments? Beyond that, in what ways do or ought such practical, everyday activities of talking and listening figure into the format and content in the variety of other forms of written documentation, such as the ethics consultant's personal notes, chart notes, case presentations, and so on, as well as writings intended as a critical or interpretive commentary on a specific situation, topic, or theme for professional presentation and publication?

Certainly, Finder was motivated to write this Scenario - and to continue the effort to compose it once he started - by a kind of "hopefulness" that he might learn something about his own practice. And evident in that hopefulness are clear presumptions, not the least of which is that there was something going on in the conversations and interactions he had in the course of this consultation that was worth trying to identify and then reflect upon. In that way, the Zadeh Scenario - both in the moments of being written and when that writing was finally "completed" - is open, not merely in the sense of it being a fragment and hence "unfinished" or "unpolished," but also open in the sense of being open to interpretation. Said more simply, the Zadeh Scenario was written as a way to discover something regarding the conduct of ethics consultation - but what that "something" is was not pre-configured, not pre-established, not pre-determined. Accordingly, as stated above, the Scenario was, and continues to be, open to and available for interpretation.

As a fragment, the Zadeh Scenario therefore allows for another sort of openness in its own implication of the larger narratives that did occur and can be imagined although these are not described or documented in the Scenario. Anticipating the typical possibilities which might have occurred, our commentators make great use of this opportunity to imagine. Again, we are exceedingly grateful for their curiosity and persistence as we worked through the different stages in the development for this Project.

With all of that said, the Zadeh Scenario is published here as a whole fragment and presented with a priority of place at the beginning of the book. As the unaltered touchstone for each essay, it functions as the primary source of themes and thus orients the essays that follow and refer to it. This priority and function in the design of the Zadeh Project create the specific context where the Scenario evokes for our collaborators in this project a set of questions and the need for careful interpretation analogous to those questions and insistent needs that characterize the kind of conversations and inquiries that occur in clinical encounters that involve clinical ethics consultants.

having developed within an amalgamation of historical and linguistic practices and genres, may obscure other relevant issues due to the limitations within one or another of worldviews actually involved. See especially Chambers 1994, 1996; Crigger 1995. 
Precisely in that context, we need to be explicit about the function of the Zadeh Scenario in that analogy. The analogy we are using has several different elements. The first is that ethical issues in clinical situations are complex - due to the many conceptual and practical commitments embedded in the languages, attitudes, historical and social conventions specific to clinical life. The second is that the "normal way of life" in clinical work is far less stable and guaranteed than it often appears. Indeed, one hallmark of clinical ethics work is its demand (even though not heeded as often as it should be) specifically not to take for granted what is otherwise taken for granted in daily institutional life.

It is that second element which creates an identifiable and crucial component of the complex analogy presented to the individuals invited to contribute to the Zadeh Project. Not only does this story of the Zadeh Scenario illustrate the need for careful appreciation of the unique and particular ways by which the "typical" and "routine" continually result in interactions and outcomes that cannot be predicted, or that confound and go awry - so much so, indeed, that there develop typical ways to deal with the "atypical" 10 - but it also does not present a "case" in a written format typical for "case presentations." In other words, presented in the ordinary everydayness that Finder describes, the Zadeh Scenario solicits from our contributors - again, analogous to the ways that people in clinical situations continually trace out and revise the context and meaning of what they are going through - that specific need for careful appreciation and appraisal of morally relevant features along a considerable range of possibilities.

In that evocative and imaginative way, and emerging directly out of a mosaic of intersections among many different and multiple discourses that compose the field of clinical ethics consultation, ${ }^{11}$ the essays that follow after the Zadeh Scenario in Part Two, Part Three, and Part Four contribute a set of rich and lucid discussions that raise sharp questions in response to the ongoing call and clamor about the need for standardized procedures, criteria, and initiatives to credential individual ethics consultants and to certify a range of qualifications. ${ }^{12}$ Far from its original, personal, and possibly idiosyncratic origin, the Zadeh Scenario is presented here, as it was presented to our various collaborators beginning with those who participated with us in 2010 for that first panel, with an aim of using and illustrating this documentary

\footnotetext{
${ }^{10}$ Alfred Schutz and Thomas Luckman note that "what is taken for granted does not form a closed, unequivocally articulated and clearly arranged province." Instead, any situation "is surrounded by uncertainty." Also, what is considered typical are typifications prominent in the stock of knowledge that "presents solutions to problems of my previous experiences and acts" (Schutz and Luckman 1973: 9).

${ }^{11}$ We can include here, as examples of such multiple discourses, the discussions about expertise, the standing of moral theories for what is called "practical ethics," as well as discussions regarding the influence of those contentious discourses in the history and development in the field of clinical ethics. See in particular Scofield 2008; Bishop, Fanning, and Bliton 2010; Engelhardt 2012; Callahan 2015.

${ }^{12}$ For instance, the credentialing and certification effort of the ASBH Quality Attestation initiative, as discussed in Kodish et al. 2013, garnered a lot of attention - and critique, which critique continues, as displayed in several of the contributions to this book.
} 
method to discover more about what matters and what may be at stake in the actual practice and growing field of clinical ethics consultation.

\section{An Enduring Theme: Voices, Talking and Listening}

No surprise to us, our invitation to our colleagues to critically engage the Zadeh Scenario resulted in the numerous voices and multiple, complex perspectives that readers will encounter in Parts Two, Three, and Four. Their responses reveal much about the diverse standpoints in this field, and plainly show the way these standpoints can and do influence understandings about ethics consultation, clinical practice, and writing about both.

In any development of peer review and credentialing for ethics consultants, considerations about precisely this sort of diversity and complexity will need to be explicitly addressed. As we mentioned earlier, within the design for this Project is a commitment to probe the idea that there are unmistakable needs to accurately interpret, understand, and tell about the different voices that occur in clinical encounters. These needs require explicit moral attention, because, as Zaner has discussed, "among the other voices choired within any encounter one can readily discern the reverberation of moral feelings embodied in images, noises, and gestures, expressed in personal and social discourses - and the urgencies to be heard, even merely noticed" (Zaner 2015: 114). It is these specific activities of interpreting, understanding, and telling in clinical circumstances that provide the most immediate kind of disclosure of individuals as they interact. "For in these encounters," Zaner says elsewhere, "the whole point is that unique individuals are caught up with one another whether as patients, families, or providers - and to say what that means, what each experiences, and the like, can only mean 'to tell the story"' (Zaner 2010: 274).

The theoretical and practical dimensions of clinical ethics consultation are wideranging and complex. As mentioned earlier in this Introduction, a theme prominent for the Zadeh Project is that the clinical and moral work of ethics consultation is primarily communicative, involving many varied forms of listening and telling, and so it is to those communicative dimensions that we must pay careful attention. Clinical ethics consultation, as a practice, is defined and determined by the actual circumstances encountered - a proposal consonant with what Schutz advocated as a principle of method for any serious and rigorous approach to human situations (Schutz 1967b; Schutz and Luckman 1989). This method allows the necessary access to the professional circumstances and sociality of many different and heterogeneous moral stories and claims about moral life. In the concluding chapter we will take up several concerns of this sort about moral stories and claims about moral life in the practice of clinical ethics consultation and the endeavor of peer review and peer learning.

These considerations all contribute to the ongoing work of identifying and probing those experiential and normative positions presented in the multiple arenas of health care, including the set of considerations about human needs and the demands 
of a shared moral life which emphasizes both understanding and incorporating a plurality of values. After all, although it remains true that every ethical view makes demands on our lives, our actions, and our own commitments, it may well turn out that there is no one correct sort of moral approach, or ethics for that matter; in fact, there very well may be many different options through which to possibly resolve morally complex circumstances (Finder and Bliton 2008). As a result, one realm of clinical ethics directs its attention to inquiring about and pursuing ways that we might understand and incorporate such a plurality of values, and thus live together among our differences. Another realm, as it begins to come into focus, insistently shows our need to fashion and identify those institutions that will support this end.

For example, in addition to using their own professionally derived knowledge and typified understanding of both clinical situations and written commentary about clinical ethics, each of our contributors has his or her own way to interpret the role of ethics consultation in the social environment in which she or he practices, as well as the status for that role in the organization and clinical environments where she or he works. Likewise, within their specific contexts, each has her or his own way to encounter, interpret, and understand what it is like to undergo the hardship of severe moral disquiet, or to be confronted with the sharp and even ultimate issues of human life - such as those that confront the family in the Zadeh Scenario: the experience of a loved one's chronic disease, issues of loss, the limitations of contemporary medical practices to alter these, and the undergoing of rage and guilt and grief. On the basis of his or her own practical experience, each engages in that characteristic activity of focusing and thinking about the efforts and actions specific to his or her own clinical practice of ethics consultation, as well as those moral experiences undergone in that practice. Hence, a defining feature that makes this "clinical" is that this type of reflective vigilance or attentiveness is not merely required, but furthermore the degree of rigor exercised in its inherent "intention" shifts the focal concern (Zaner 1975).

In more straightforward terms, this "intention" characterizes the sustained focus and rigor for a kind of clinical ethics detective work. Consider this kind of shift in intentional focus when it becomes personal, as one collected group of ethicists has explained regarding this exact point: when it is you or your loved one who becomes the patient confronted "face to face with mortality, loss of control, vulnerability and increased dependence," it turns out to be quite a different experience (Dresser 2011: 14). When it is you or your loved one, they insist, we become more alert to "the ethical significance of what some might regard as trivial elements of patient care" (Dresser 2011: 15). In this light, one participant observed that "doctors and nurses make 'constant small ethical decisions [in their] everyday clinical work,' like whether to make eye contact with the patient or take seriously the patient's complaints" (Dresser 2011: 15). In other words, another said, "Without a good understanding of what it is like to be overwhelmed by the experience of illness-one's own or that of a loved one-how can the doctor or ethicist appreciate the human situation the doctor must address?" (Dresser 2011: 17).

In a similar way, our contributors "document" in their writing these pivotal elements of focusing and thinking about the efforts and actions specific to clinical 
ethics consultation. Incorporated in their "documentation" are those specific sets of situations, expectations, norms and so on, that each has encountered, interpreted, and then utilized in his or her experience of moral issues, social concerns, and institutional attitudes in clinical work - embedded as all those elements are in their own experiences in clinical routines and practices, along with the specific history and formation of their own professional roles and activities. In summary, their contributions "document" critical ways to understand the broad and extensive array of critical issues and questions regarding what might be at stake in the telling of the Zadeh Scenario, and at the same time, the Scenario also represents simply another set of experiences in a series of everyday occurrences. That is to say, our contributors illustrate the multiple ways that clinical ethics and related matters are understood from their role as peer reviewers and commentators and, likewise, clearly show how the range of interpretations woven throughout these different chapters serve as exemplars for describing the contents not merely of "ethical problems" but also, and perhaps most importantly, what it could mean to "do" clinical ethics consultation.

As we did when initially sending all of our collaborators the invitation to join us in this exploration, we now invite you, the reader, to join us as well in this process of discovery, this effort to be open, this work of giving voice to what might be held as meaningful at the root of clinical ethics practice; this, in short, is the ultimate aim of the Zadeh Project.

\section{References}

Andre J (2002) Bioethics as practice. University of North Carolina Press, Chapel Hill

Anspach R (1995) Deciding who lives: fateful choices in the intensive-care nursery. University of California Press, Oakland

Aulisio MP, Arnold RA, Youngner SJ (2003) Ethics consultation: from theory to practice. John Hopkins University Press, Baltimore

Bishop JP, Fanning JB, Bliton MJ (2010) Echo calling narcissus: what exceeds the gaze of clinical ethics consultation. HEC Forum 22(1):73-85

Bliton MJ (2005) Richard Zaner's "troubled" voice in Troubled Voices: poseur, posing, possibilizing? Theor Med Bioeth 26(1):25-53

Bliton MJ, Finder SG (2002) Traversing boundaries: clinical ethics, moral experience, and the withdrawal of life supports. Theor Med Bioeth 23(3):233-258

Bosk CL (2009) What would you do? juggling bioethics and ethnography. University of Chicago Press, Chicago

Bruce CR, Smith ML, Tawose OM, Sharp RR (2014) Practical guidance for charting ethics consultations. HEC Forum 26(1):79-93

Bruce CR, Eves MM, Allen NG et al (2015) "Systematizing" ethics consultations services. HEC Forum 27(1):35-45

Callahan D (2015) What is it to do good ethics? J Med Ethics 41(1):68-70

Chambers TS (1994) The bioethicist as author: the medical ethics case as rhetorical device. Lit Med 13(1):60-78

Chambers TS (1996) From the ethicist's point of view: the literary nature of ethical inquiry. Hastings Cent Rep 26(1):25-33

Chambers TS (2000) Why ethicists should stop writing cases. J Clin Ethics 11(3):206-218 
Churchill LR, Fanning JB, Schenk D (2013) What patients teach: the everyday ethics of health care. Oxford University Press, New York

Crigger BJ (1995) Negotiating the moral order: paradoxes of ethics consultation. Kennedy Inst Ethics J 5(2):89-112

Curtis JR, Engelberg RA, Bensink ME et al (2012) End-of-life care in the intensive care unit: can we simultaneously increase quality and reduce costs? Am J Respir Crit Care Med 186(7):587-592

Dresser R (2011) Bioethics and cancer: when the professional becomes personal. Hastings Cent Rep 41(6):14-18

Dubler NN, Webber MP, Swiderski DM et al (2009) Charting the future: credentialing, privileging, quality, and evaluation in clinical ethics consultation. Hastings Cent Rep 39(6):23-33

Engelhardt HT (1996) The foundations of bioethics, 2nd edn. Oxford University Press, New York

Engelhardt HT (2012) A skeptical reassessment of bioethics. In: Engelhardt HT (ed) Bioethics critically reconsidered. Philosophy and medicine 100. Springer, New York, pp 1-30

Evans JH (2012) The history and future of bioethics: a sociological view. Oxford University Press, New York

Finder SG (2018) The Zadeh scenario. In: Finder SG, Bliton MJ (eds) Peer review, peer education, and modeling in the practice of clinical ethics consultation: the Zadeh project. Springer, Cham, pp 21-42

Finder SG, Bliton MJ (2008) Responsibility in actual practice: consent and participation in clinical ethics consultation. In: Hester M (ed) Ethics by committee: a textbook on consultation, organization, and education. Rowman \& Littlefield, Lantham, pp 79-106

Finder SG, Bliton MJ (2011) Responsibility after the apparent end: "following-up" in clinical ethics consultation. Bioethics 25(7):413-424

Fins JJ, Kodish E, Cohn F et al (2016) A pilot evaluation of portfolios for quality attestation of clinical ethics consultants. AJOB 16(3):15-24

Foglia MB, Fox E, Chanko B, Bottrell MM (2012) Preventive ethics: addressing ethics quality gaps on a systems level. Jt Comm J Qual Patient Saf 38(3):103-111

Ford PJ, Dudzinski DM (eds) (2008) Complex ethics consultations: cases that haunt us. Cambridge University Press, Cambridge

Fox RC, Swazey JP (2008) Observing Bioethics. Oxford University Press, New York

Frank AW (1997) Illness as moral occasion: restoring agency to ill people. Health Interdiscip J Soc Study Health Illn Med 1(2):131-148

Frank AW (2001) Experiencing illness through storytelling. In: Kay Toombs S (ed) Handbook of phenomenology and medicine. Philosophy and medicine series, vol 68. Kluwer Academic Publishers, Dordrecht, pp 229-246

Frank AW (2004) Ethics as process and practice. Intern Med J 34(6):355-357

Freedman B, Weijer C, Brereza E (1993) Case notes and charting of bioethics case consultations. HEC Forum 5(3):176-195

Gaines AD, Juengst ET (2008) Origin myths in bioethics: constructing sources, motives and reason in bioethic(s). Cult Med Psychiatry 32(3):303-327

Garfinkel H (1967) Studies in ethnomethodology. Prentice-Hall, Inc., Englewood Cliffs

Hoffmaster B (1992) Can ethnography save the life of medical ethics? Soc Sci Med 35(12):1421-1431

Jecker NS, Jonsen AR, Pearlman RA (eds) (2012) Bioethics: an introduction to the history, methods and practice, 3 rd edn. Jones \& Bartlett, Sudbury

Jonsen AR, Toulmin S (1988) The abuse of casuistry: a history of moral reasoning. University of California Press, Los Angeles

Kaufman S (2015) Ordinary medicine: extraordinary treatments, longer lives, and where to draw the line. Duke University Press, Durham

Kleinman A (1988) The illness narratives: suffering, healing, and the human condition. Basic Books, New York

Kleinman A (2006) What really matters: living a moral life amidst danger and uncertainty. Oxford University Press, Oxford 
Kodish E, Fins JJ, Braddock C et al (2013) Quality attestation for clinical ethics consultants: a two-step model from the American society for bioethics and humanities. Hastings Cent Rep 43(5):26-36

Komesaroff P (2001) The many faces of the clinic: a Levinasian view. In: Kay Toombs S (ed) Handbook of phenomenology and medicine. Philosophy and medicine series, vol 68. Kluwer Academic Publishers, Dordrecht, pp 317-330

MacIntyre A (1984) After virtue, 2nd edn. University of Notre Dame Press, Notre Dame

Molewijk B, Kleinlugtenbeit D, Pugh SM et al (2011) Emotions and clinical ethics support: a moral inquiry into emotions in moral case deliberation. HEC Forum 23(4):257-268

Molewijk B, Widdershoven G, Vollman J, Schildmann J (2016) What quality is actually assessed within written records? AJOB 16(3):48-50

Natanson M (1970) The journeying self: a study in philosophy and social role. Addison-Wesley Publishing Co., Reading

Nelson WA, Gardent PB, Shulman E, Splaine ME (2010) Preventing ethics conflicts and improving healthcare quality through system redesign. Qual Safe Health Care 19:526-530

Pearlman R, Foglia MB, Fox E et al (2016) Ethics consultation quality assessment tool: a novel method for assessing the quality of ethics case consultations based on written records. AJOB 16(3):3-14

Rasmussen L (2018) Standardizing the case narrative. In: Finder SG, Bliton MJ (eds) Peer review, peer education, and modeling in the practice of clinical ethics consultation: the Zadeh project. Springer, Cham, pp 151-160

Rogers MF (1983) Sociology, ethnomethodology, and experience: a phenomenological critique. Cambridge University Press, London

Rosell T, Johnson B (2018) This may, or may not, be an ethics consultation. In: Finder SG, Bliton MJ (eds) Peer review, peer education, and modeling in the practice of clinical ethics consultation: the Zadeh project. Springer, Cham, pp 99-107

Schutz A (1967a) The phenomenology of the social world (trans: Walsh G, Walsh FLG). Evanston: Northwestern University Press

Schutz A (1967b) Sartre's theory of the alter ego. In: Natanson M (ed) Collected papers I: the problem of social reality, 2nd unchanged edn. Martinus Nijhoff, The Hague, pp 180-203

Schutz A, Luckman T (1973) Structures of the life-world, vol I (trans: Zaner RM, Engelhardt HT). Evanston: Northwestern University Press

Schutz A, Luckman T (1989) The structures of the life-world, vol II (trans: Zaner RM, Parent DJ). Evanston: Northwestern University Press

Scofield GR (2008) What is medical ethics consultation? J Law Med Ethics 36(1):95-118

Speigelberg H (1975) Doing phenomenology: essays on and in phenomenology. Martinus Nijoff, The Hague, pp 68-69

Starr P (1982) The social transformation of American medicine: the rise of a sovereign profession and the making of a vast industry. Basic Books, New York

Zaner RM (1975) On the sense of method in phenomenology. In: Pivcevic E (ed) Phenomenology and philosophical understanding. Cambridge University Press, London, pp 125-141

Zaner RM (1981) The context of self: a phenomenological inquiry using medicine as a Clue. Ohio University Press, Athens

Zaner RM (1984) Is "ethicist" anything to call a philosopher? Hum Stud 7(1):71-90

Zaner RM (1988) Ethics and the clinical encounter. Prentice-Hall, Inc., Englewood Cliffs (reprinted in 2002 by Academic Renewal Press)

Zaner RM (1993) Troubled voices: stories of ethics and illness. The Pilgrim Press, Cleveland

Zaner RM (1998) In response: what's it really all about? Hum Stud 21(1):63-70

Zaner RM (2004a) Conversations on the edge. Georgetown University Press, Washington, DC

Zaner RM (2004b) Physicians and patients in relation: clinical interpretation and dialogues of trust. In: Khushf G (ed) Handbook of bioethics: taking stock of the field from a philosophical perspective. Kluwer Academic Publishers, Dordrecht/Boston, pp 223-250 
Zaner RM (2006) The phenomenon of vulnerability in clinical encounters. Hum Stud 29(3):283-294

Zaner RM (2010) A phenomenological reflection conducted through narrative: an essay in honor of Lester Embree. In: Nenon T, Blosse P (eds) Advancing phenomenology: essays in honor of Lester Embree. Springer, New York, pp 271-301

Zaner RM (2015) A critical examination of ethics in health care and biomedical research: voices and vision. Springer, New York

Zussman R (1992) Intensive care: medical ethics and the medical profession. University of Chicago Press, Chicago

Open Access This chapter is licensed under the terms of the Creative Commons Attribution 4.0 International License (http://creativecommons.org/licenses/by/4.0/), which permits use, sharing, adaptation, distribution and reproduction in any medium or format, as long as you give appropriate credit to the original author(s) and the source, provide a link to the Creative Commons license and indicate if changes were made.

The images or other third party material in this chapter are included in the chapter's Creative Commons license, unless indicated otherwise in a credit line to the material. If material is not included in the chapter's Creative Commons license and your intended use is not permitted by statutory regulation or exceeds the permitted use, you will need to obtain permission directly from the copyright holder.

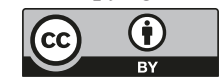

